la colección Karate Superior una andadura a través de los Katas del estilo Shotokan, la cual es de esperar tenga su continuidad con los volúmenes siguientes dedicados a Katas superiores, e incluso que la Editorial Tutor no se limite a la edición de los tomos 6,7 y 8 de la colección (en castellano), sino que proceda a la publicación de los volúmenes 9, 10 y 11 (publicados en otros idiomas) de esta inmejorable colección de libros técnicos de Karate.

El planteamiento que el Maestro Nakayama recoge en estos textos ha tenido enorme influencia en los practicantes de todo el mundo en materia de Katas de Karate del estilo Shotokan, existiendo incluso material videográfico de apoyo sobre esta extensa tarea que el propio autor supervisó antes de su fallecimiento.

Técnicamente correctos e ilustrados de manera adecuada, Katas Heian y Tekki aportan de manera sencilla y completa un estudio sobre los ejercicios que conforman el Karate, aportando un planteamiento progresivo en su aprendizaje y avalados por la autoridad de su autor, el Maestro Nakayama, así como por la corrección en la ejecución de sus instantáneas gracias a la facilidad con la que el Maestro Osaka muestra los ejercicios.

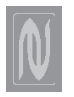

\section{La lucha, los aluches y los juegos populares $y$ aristocráticos en la li- teratura española}

Por José Antonio Robles Tascón.

León: Universidad de León, 2003.

206 páginas. $22 \times 28 \mathrm{~cm}$. Ilustraciones.

I.S.B.N.: 84-9773-011-9.

\section{Disponible en:}

Secretariado de Publicaciones y Medios Audiovisuales.

Universidad de León.

Campus de Vegazana, s/n.

24071-LEÓN

ESPAÑA.

Tfno.: +34987291166

Fax.: +34987291166

E-mail: recsp@unileon.es
Revisión por Eduardo Álvarez del Palacio.

La obra consta de un extraordinario prólogo firmado por el Profesor e insigne leonés Don Miguel Cordero del Campillo, Catedrático Emérito de la Facultad de Veterinaria de la Universidad de León, y tres capítulos, con un total de doscientas seis páginas.

El contenido del primer capítulo recoge una aproximación a los principios de la actividad físico-lúdica en la España del siglo XVI: las diversiones y pasatiempos del pueblo y de la nobleza. Será en el trabajo y en los momentos de descanso que este procura -el ocio-, donde se encuentran los pilares sobre los que se asienta la razón primera de los juegos y deportes practicados por nuestros antepasados del Siglo de Oro, significando para ellos una forma de diversión y de esparcimiento. Esta actividad también enlazará con otros campos de estudio durante esta época, como por ejemplo el de la higiene médica y el de la educación. Así, el ejercicio corporal será recogido y llevado a la práctica por los principales tratadistas médicos, como es el caso de Luis Lobera, Cristóbal Méndez, Francisco Núñez de Coria, Blas Álvarez de Miraval, Juan Sorapán de Rieros, etc. También en la literatura pedagógica de la época, plasmada en los conocidos tratados de educación de príncipes, se elogia el ejercicio físico-corporal como un medio imprescindible en la formación integral de los jóvenes nobles, destacando el valor del juego como una actividad transmisora de valores ético-morales y de sociabilidad fundamentales, siendo buena prueba de ello las obras del Padre Juan de Mariana, de Fray Alonso Remón, de Saavedra Fajardo, de Luis Vives, de Fray Francisco de Alcocer, de Antonio de Lebrija, de Lorenzo Palmireno, etc.

El segundo capítulo está dedicado al estudio de los juegos, ejercicios y luchas en la literatura española desde la antigüedad y hasta nuestros días. La primera noticia que tenemos de la lucha en España es facilitada por Estrabón, que nos informa sobre la costumbre de luchar como una práctica muy extendida entre todas las tribus del norte peninsular. También San Isidoro, en sus Etimologías, se refiere a la lucha como una práctica ancestral y muy extendida en su época. Alonso de Ercilla y Zúñiga en el poema épico La Araucana, describe detalladamente los certámenes de lucha celebrados. Y así hasta nuestros días, una gran cantidad de significados personajes de la literatura española se referirán a la lucha como una práctica popular de importante valor sociocultural.

El contenido del tercer capítulo recoge la consideración de los aluches en la obra de los principales escritores leoneses. Se inicia el estudio en los Coloquios pastoriles (1553), del maragato Antonio de Torquemada, en los que se refiere a esta actividad como una práctica habitual entre los pastores; y llega hasta José Millán Urdiales, que en su obra titulada El habla de Villacidayo (1966), publicada por la Real Academia Española de la Lengua, dedica un capítulo a los pasatiempos de sus paisanos, con especial énfasis en los aluches.

Así, en la literatura leonesa encontramos referencias a la antigüedad de esta práctica, la variedad de sus formas y modos de luchar, de cuándo y cómo se desarrollaba el ritual de los corros de aluches, provocando en el ánimo de los escritores leoneses un sentimiento de apoyo literario a esta práctica ancestral de su tierra.

Para finalizar esta breve reseña, y como corolario de la misma, retomo las palabras del profesor Cordero del Campillo en su prólogo: "esta obra supone una importante contribución a la Historia de la lucha leonesa, y su lectura constituirá un apoyo a la práctica de este deporte tradicional, que afortunadamente está prendiendo entre nuestros jóvenes de las ciudades, con lo que parece conjugado el riesgo del olvido, consecuencia de la desaparición de nuestros pueblos".

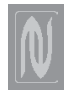

\section{Aikido. El Maestro y el Método}

Por Tomás Sánchez Díaz

Móstoles: Arkano Books, (2001, $3^{\mathrm{a}}$ ed.)

192 páginas. $17 \times 24 \mathrm{~cm}$. Ilustraciones I.S.B.N.: 84-89897-40-9 • 15,00€

Disponible en:

Distribuciones y Ediciones Alfaomega 